\title{
Is the company under monopolistic competition?
}

Luwak Coffee or which is known globally as Kopi Luwak comes from Indonesia is a typical niche product of PTP XII. PTPN XII is a state-owned plantation that grows a number of crops, such as Kopi Luwak, tea and other coffee beans. The word "Kopi" refers to the local word for "Coffee" and Luwak is the local name for Asian Palm Civet. Kopi Luwak has a distinct taste that is not as bitter as a normal coffee and has an earthy taste to it. (Pratono \& Radjamin, 2012)

The reason the coffee is so pricey is because the local farmers collect the feces of the civet and pick out the beans one by one, wash and dry them under the sun. (Pratono \& Radjamin, 2012) In 2010, the company attempt to change 2,520 t of Arabica coffee to Kopi Luwak because the quantity of their production wasn't able to achieve the huge demand needs. Is the company under monopolistic competition?

Monopolistic competition is a situation where there are a lots of firms competing but each firm has some degree of market, and each of the firm has some choice over what price to charge for its products. Prices are independent of the number of competitors in the CES model of monopolistic competition. We can conclude that the demand side is more important to generate a general equilibrium model of monopolistic competition. (Parenti, Ushchev, \& Thisse, 2016) The primary ingredient that any model of monopolistic competition should carry is the heterogeneity in consumer preferences. (Osharin, Thisse, Ushchev, \& Verbus, 2013)

The company PTPN XII is under a monopolistic competition because they sell a regular product but with a different twist in it that not all of the producers have it, which is producing Kopi Luwak. They also actively advertise and sell their products to the local market, also exports to another country such as Japan and China. In 2011, the Rollaas Cofe in Tunjungan provide the highest income of more than $\$ 20,000 /$ month. In local market, the café industry has been growing remarkably over the last decades with $9,3 \%$ growth. Firms are assumed to adjust the prices of their products in order to maximize their profits. (Sakane, 2015) 